\title{
Lack of application of the European Work Time Directive: effects on workload, work satisfaction and burnout among Italian physicians
}

\author{
Paola Gnerre, ${ }^{1}$ Domenico Montemurro, ${ }^{2}$ Andrea P. Rossi, ${ }^{3}$ Costantino Troise,${ }^{4}$ Carlo Palermo, ${ }^{5}$ Dario Amati, ${ }^{6}$ \\ Chiara Rivetti, ${ }^{7}$ Matteo D’Arienzo, ${ }^{8}$ Gabriele Romani, ${ }^{9}$ Fabio Ragazzo 9
}

${ }^{1}$ Department of Internal Medicine, San Paolo Hospital, Savona; ${ }^{2}$ Department of Internal Medicine, Sant'Antonio Hospital, Padova; ${ }^{3}$ Department of Medicine, Division of Geriatrics, University of Verona; ${ }^{4}$ Department of Allergology, IRCSS San Martino, Genova; ${ }^{5}$ Department of Internal Medicine, Valdelsa Hospital, Poggibonsi (SI); ${ }^{6}$ Department of Medicine, Division of Geriatrics, Nuovo Ospedale degli Infermi, Biella; ${ }^{7}$ Department of Internal Medicine, Maggiore Hospital, Chieri (TO); ${ }^{8}$ Department of Emergency, Magati Hospital, Scandiano (RE); ${ }^{9}$ Department of Medicine, Division of Medicine, San Bortolo Hospital, Vicenza, Italy

\begin{abstract}
The Italian Parliament has excluded hospital physicians from the application of the European Work Time Directive (EWTD), which imposes a maximum workweek of $48 \mathrm{~h}$ and compulsory resting periods. This resulted in extended and excessive work time for the category. This paper is aimed at evaluating the impact of this legislation gap, by assessing the presence of excessive work-related stress and risk for burnout syndrome among Italian physicians working in public hospitals. This observational study is based on an on-line survey conducted on a sample of 1925 Italian doctors (covering a wide range of age, work experience and contractual positions) from October 2014 to February 2015. The questionnaire included 30 questions concerning their personal and professional life (e.g., assessment of workloads, number of uncomfortable or extra shifts, unused days-off, etc.). On the basis of the results, it can be inferred that the average Italian doctor working in public hospitals is under considerable stress at work with negative consequences on his health. He is exposed to high risk of suffering from sleep disorders and cardiovascular diseases (due to the lack of time for private practice and eating regular meals). Overall, his perception is that his job worsens his quality of life. This study shows the relevance of the risk of burnout among Italian physicians employed in public hospitals due to severe workload and work conditions. The resulting impact on the quality of care and the significant cost involved - both in human and economic terms - calls for significant emergency measures by the Italian health work organization. An important increase and prolonged working time is associated with a worsening of the objective cognitive performance and an increase of clinical risk, but also to an increased risk of diseases for operators and of the burnout syndrome. Our survey shows that lack of application of the EWTD has adverse effects on the quality of life and performance of Italian doctors. Failure to respond by all Italian doctors is the greatest limitation of our survey.
\end{abstract}

Correspondence: Paola Gnerre, Department of Internal Medicine, San Paolo Hospital, via Genova 30, 17100 Savona, Italy. Tel.: +39.019.8404358 - Fax: +39.019.8404583.

E-mail: pgnerre@yahoo.it

Key words: Burnout; European Work Time Directive; workload.

Conflict of interest: the authors declare no potential conflict of interest.

Received for publication: 12 March 2016.

Revision received: 10 August 2016.

Accepted for publication: 23 August 2016.

This work is licensed under a Creative Commons Attribution NonCommercial 4.0 License (CC BY-NC 4.0).

CCopyright P. Gnerre et al., 2017

Licensee PAGEPress, Italy

Italian Journal of Medicine 2017; 11:159-163

doi:10.4081/itjm.2017.714

\section{Introduction}

Herbert Freudenberger, an American psychologist, spoke for the first time of burn-out in 1970 to describe the consequences of severe stress and high ideals experienced by healthcare workers, particularly physicians. The health professional subjected to excessive workloads and stress gradually loses empathy and the so-called professional death (i.e., a complete indifference to his/her profession). Among physicians, the development of burnout acquires significant attention because physicians who had high burnout levels reportedly committed more medical errors. At present, there is no generally valid, internationally agreed definition of burnout or a valid instrument for the differential diagnosis of burnout syndrome. The most frequently used screening instruments are the Maslach burnout inventory and the burnout measure. ${ }^{1}$ Both involve an assessment of the following three dimen- 
sions: emotional exhaustion, depersonalization and personal accomplishment.

Emotional exhaustion, alienation from work activities with change in behavior at workplace and reduced performance are three main areas of symptoms that are considered to be signs of burnout syndrome. Therefore, the term burnout defines an individual exhausted, listless, and unable to cope.

Nowadays, the term is not only used for care giving professions but for any individual undergoing an excessive work related stress state. The burnout syndrome has become a mass phenomenon receiving constant media attention.

However, generic factors such as global stress and life satisfaction may contribute to the cause of burnout. $^{2}$

\section{Materials and Methods}

A questionnaire was sent to Italian doctors working in hospitals by private email and through a protected online site (October 2014-February 2015). The questionnaire included 30 questions concerning personal and professional life and was aimed at evaluating the presence of excessive stress related to increased workloads. Factor analysis and test reliability for the survey was determined. Mean scores for the subscales determining burnout, namely emotional exhaustion, depersonalization and lack of personal accomplishment were calculated. Table 1 shows some questions in the survey.

\section{Results}

A total of 1925 physicians responded to the questionnaire; $43.68 \%$ female, $56.32 \%$ male. $42.96 \%$ $(\mathrm{n}=827$ physicians) are aged 51-60 years, $22.39 \%$ $(\mathrm{n}=431)$ are aged $41-50$ years, $18.75 \%(\mathrm{n}=291)$ are aged $30-40$ years, the $14.55 \%(n=280)$ are aged 61 and $>65$ years, $1.35 \%(\mathrm{n}=26)$ are less than age 30 .

The majority of respondents (44.23\%) work in Northern Italy, 35.05\% (674) work in central Italy, $8.88 \%$ (171) work on one of the islands (Sicily and Sardinia) and only $11.84 \%$ (228) work in southern Italy. The regions most represented are Emilia Romagna $(14.6 \%)$ followed by Piedmont (14:34\%), Veneto (10.81\%) and Lombardy (9.97\%).

The majority of respondents work in large urban centers (Turin, 9.36\%, Rome 7.48\%, Milan 3.48\%). $56.34 \%$ of respondents have a permanent job for more than 15 years (hired before year 2000). $7.17 \%$ have a permanent employment contract for less than 5 years. Overall, $90.25 \%$ of respondents (1738) have a permanent employment contract. Only $0.42 \%$ of responders are outpatient specialists, and only $1.19 \%$ have an atypical employment contract (form of flexible work, Figure 1).
Correlating age with type of contract: $45.5 \%$ $(n=162)$ of respondents of the age group between 3040 years (361 total) have a permanent employment contract between $5-15$ years, $22.6 \%(\mathrm{n}=81)$ have a permanent employment contract for less than 5 years, $17.4 \%(\mathrm{n}=60)$ are residents, while $7.5 \%$ have a temporary employment contract (34) and atypical employment contracts (26). 86\% ( $\mathrm{n}=711)$ of respondents of the largest class (between 51-60 years) have a permanent employment contract for more than 15 years, $11 \%(\mathrm{n}=91)$ have a permanent employment contract between 5 and 15 years and about $1 \%$ have a permanent employment contract for less than 5 years $(\mathrm{n}=11)$ and temporary employment contract $(\mathrm{n}=13)$.

As for the workload indicators, the following have been evaluated: i) time since the latest recruitment of a doctor in your medical staff; ii) patients for each physician; iii) night shifts per months; iv) extended work duration (work after night shift); v) total night and day shifts per months; vi) annual hours of overtime; vii) use of annual leave days. $73.59 \%$ of respondents reported that additional physicians were not employed for at least two years and for $48 \%$ of respondents at least five years. $54 \%$ of respondents care for a number of patients less than $11,20.6 \%$ between $12-16$ and $25.4 \%$ between 17 and over 22 (Figure 2).

The number of patients assigned to each physician is higher in Northern Italy than in Central, Southern and Island areas. $33.3 \%$ of respondents have from 1 to 3 night shifts per month, $25.5 \%$ from 4 to 5 night shifts, $10.8 \%$ from 6 to 7 night shifts and 5\% work more than 8 night shifts (Figure 3).

Almost a third of respondents (33\%) have affirmed to work after a night shift.

Over a third of the respondents have between 7 and 16 work shifts (day and night) every month.

Table 1. Some questions of the survey.

How many times did new employment not occur in your department?

Number of patients for physician

How many night shifts do you perform monthly?

Do you work after the night shift?

How many shifts (day + night) do you work monthly?

How many hours of overtime do you perform yearly?

Do you use all annual leaves?

Do you have any cardiovascular disease?

Do you suffer from sleep disorders and, if yes, of what type?

Do you perform a sport or a hobby?

Has your job a negative influence on your life? 
Almost $40 \%$ of respondents work on average between 150-250 additional hours every year.

For $67.8 \%$ of respondents, overtime hours are a result of chronic short-staffing of medical personnel. $41 \%$ do not recover overtime hours. More than a half of respondents do not use all their contractual leave days.

Severe workload and working conditions pose potential threats to the health of the physicians. $41 \%$ of respondents have cardiovascular and metabolic disease and $40 \%$ sleep disorders (Figure 4 ). $65 \%$ of respondents do not enjoy regular lunch breaks. 54.8\% do not partake in any regular physical activity for lack of time; only $22 \%$ do and only $14 \%$ have a hobby.

The majority of respondents believe that their job negatively affects their quality of life. $22 \%$ do not have a satisfactory private life due to hard work shifts (Figure 5).

The analysis of questionnaire shows that a severe level of burnout can be found among Italian physicians regardless of their age. Almost $80 \%$ of respondents believe that their job is worsening their quality of life and causing an excessive stress state. $40 \%$ of our respondents report sleep disorders. Poor sleep is specifically associated with burnout syndrome. A typical Italian physician in an excessive stress states that he/she is responsible alone for 12 to 22 patients, works between 7 to 16 shifts (day and night) monthly and between 4 to 8 night shifts. $\mathrm{He} /$ she does not have a regular lunch break and does not indulge in any sport or hobby for lack of time.

\section{Discussion and Conclusions}

Burnout is a common syndrome among healthcare workers, particularly physicians who are ex- posed to a high level of stress at work. Multiple studies have indicated a high prevalence of burnout among physicians and have shown that $40-50 \%$ of them have experienced such. The majority of the studies presented in the literature were conducted on doctors working in Emergency Departments and Emergency and Resuscitation Services, family doctors and residents. ${ }^{3-5}$

The aim of our study was to assess the importance of burnout cases among Italian physicians working in hospitals. The physician's hospital work is typically shift. Shift work, defined as not a regular daytime schedule, has long been known to disrupt circadian rhythm, sleep, and work-life balance. Excessive workloads have been indicated to have adverse effect on health, such as elevated risk of hypertension, cardiovascular events, metabolic syndromes and work-related accidents. ${ }^{6,7}$

Our results illustrate the challenges of Italian physicians that may impact the quality of care and possibly (or probably) contribute to work absences.

In fact, numerous studies have been shown not only the emotional cost of burnout syndrome but also its economic cost to society correlated to work absences. ${ }^{8}$ These results are in line with a recent review showing the high stress levels found in health professionals (physicians and nurses) working in Italian apheresis units.

In 2003, the European Parliament declared the European Work Time Directive (EWTD). This directive, applicable to all occupations across the European Union (EU), establishes a maximum workweek of $48 \mathrm{~h}$ and imposes rest periods. The Italian Parliament has not adopted this directive for physicians working in hospitals resulting in extended and excessive work time.

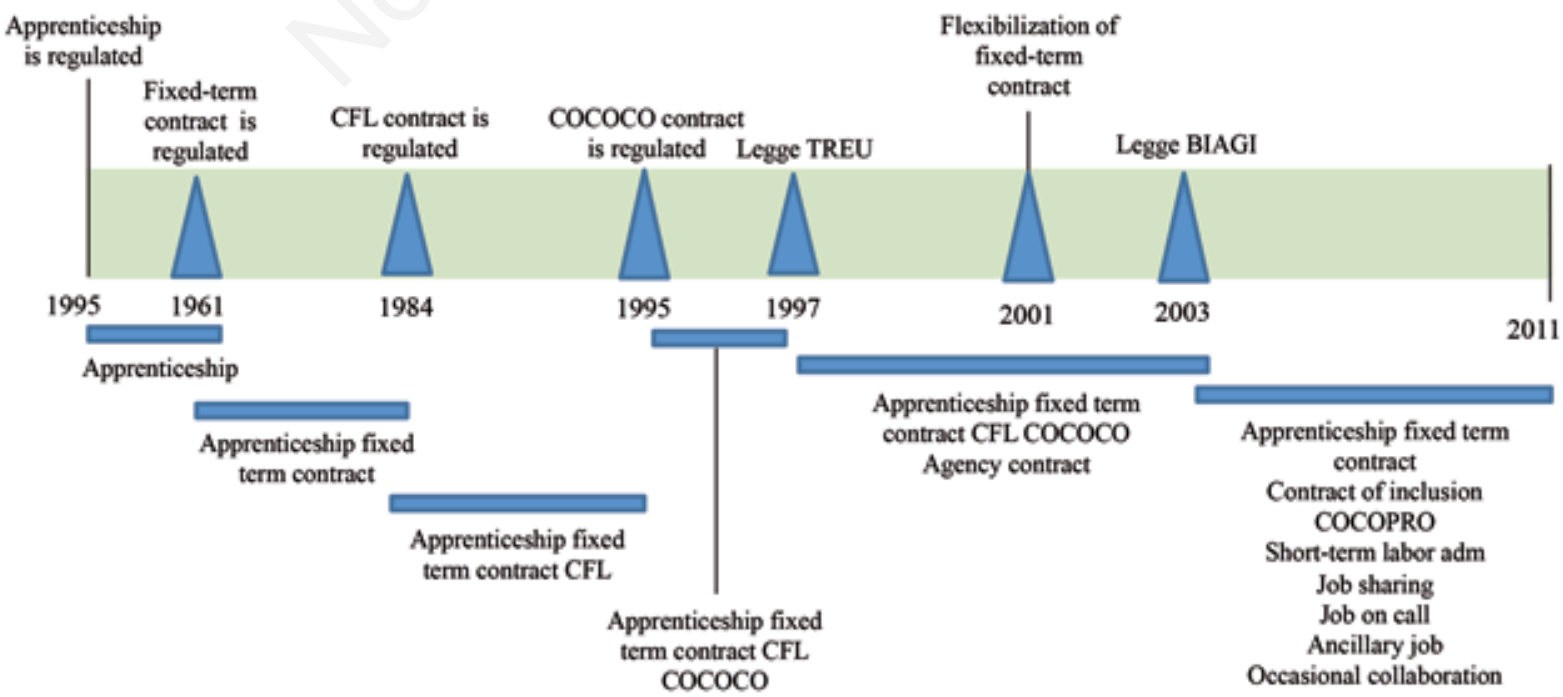

Figure 1. Atypical contracts timeline. 


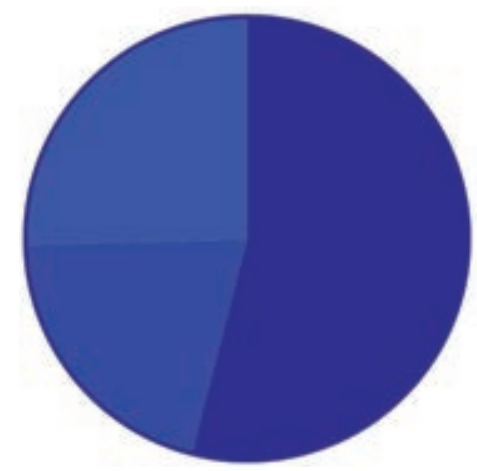

$54.00 \% \quad 0-11$ patients/physician

20.60\% 12-16 patients/physician

$25.40 \% \quad 17->22$ patients/physician

Figure 2. Number of patients/physician.

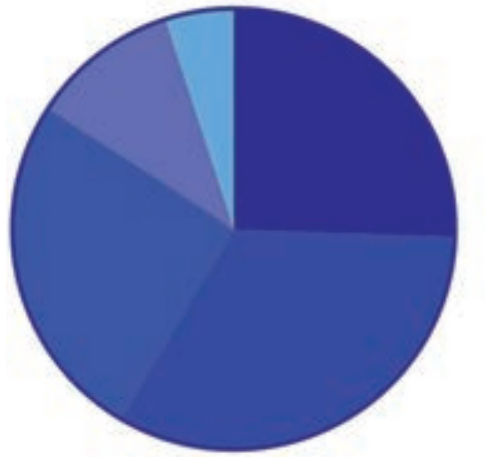

$25.53 \% 0$ night shift

$33.03 \% \quad 1-3$ night shift

$25.63 \%$ 4-5 night shift

$10.81 \% 6-7$ night shift

$5.01 \%>8$ night shift

Figure 3. Number of night shifts per months.

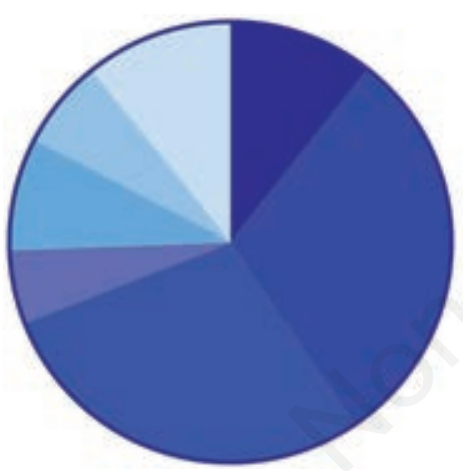

- $10.65 \%$ Daily use of hypnotic drugs

- $29.84 \%$ Delayed sleep phase syndrome

28.53\% Insomnia

$\square .41 \%$ Narcolepsy

$\square 8.20 \%$ OSAS

$\square$ 6.54\% REM sleep behavioral disorder

$\square 10.82 \%$ Restless legs syndrome

Figure 4. Type of sleep disorders.

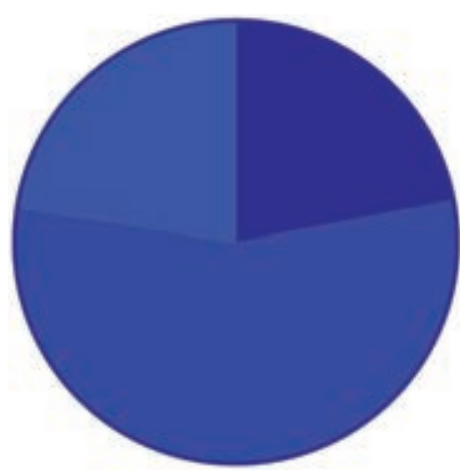

$22.00 \%$ Yes, I have a very bad private life

$55.50 \%$ Yes, I have trouble with work shifts and private life $22.50 \%$ No

Figure 5. Has your job had any negative consequence on the quality of your life? 
Therefore, Italian physicians working in hospitals are examples of workers for whom EWTDs are not applied. ${ }^{9}$

Stress management programs have been effective in preventing and treating burnout significantly enhancing physicians' quality of life. ${ }^{10}$

The use of practice programs as intensive educational program in mindfulness, communication, and self-awareness should be extended to improve working practice and professional efficiency in order to reduce occupational stress of doctors and greater job satisfaction. Training in attention, awareness, and communication skills would increase physician wellbeing, reduce psychological distress and burnout, and promote positive changes in physicians' capacity to deal with patients. The individual becomes more attentive to recognize the sources of stress and mitigate its effects. Further studies might demonstrate burnout's effect on patient safety, service quality and physician's performance (e.g., European Agency for Safety and Health at Work: https://osha.europa.eu/en/ oshnews/france-work-organisation-challenged-psychosocial-risks?pk_campaign $=032016$ ).

Within the principal limitations of the number of respondents on the national total of professionals our results involve serious emergency measures to address in the Italian health work organization and specific investigations are mandatory for Italian health authorities. Prevention and treatment must focus on improving the individual's stress coping skills, optimizing their job situation and planning more time for rest. Without urgent measures, the risk is that burnout could remain a phantom syndrome, thus highly damaging.

\section{References}

1. Kaschka WP, Korczak D, Broich K. Burnout: a fashionable diagnosis. Dtsch Arztebl Int 2011;108:781.

2. Seidler A, Thinschmidt M, Deckert S. The role of psychosocial working conditions on burnout and its core component emotional exhaustion- a systematic review. J Occup Med Toxicol 2014;9:1.

3. Magalhães E, Oliveira ÁC, Govêia CS, et al. Prevalence of burnout syndrome among anesthesiologists in the Federal District. Rev Bras Anestesiol 2015;65:104-10.

4. Tomljenovic M, Kolaric B, Stajduhar D, et al. Stress, depression and burnout among hospital physicians in Rijeka, Croatia. Psychiatr Danub 2014;26:450-8.

5. Popa F, Arafat R, Purcărea VL. Occupational burnout levels in emergency medicine--a stage 2 nationwide study and analysis. J Med Life 2010;3:449-53.

6. Najib TA, Barger L, Cade B, et al. Extended work duration and the risk of self-reported percutaneous injuries in interns. JAMA 2006;296:1055.

7. Avid D, Aba MG, Oward S. Fatigue among clinicians and the safety of patients. N Engl J Med 2002;347:16.

8. Sibinga EM. Clinician mindfulness and patient safety. JAMA 2010;304:2532-3.

9. Aksoy DY, Durusu Tanriover M, Unal S, et al. Burnout syndrome during residency in internal medicine and pediatrics in a country without working time directive. Int J Health Care Qual Assur 2014;27:223-30.

10. Krasner MS, Epstein RM, Beckman H. Association of an educational program in mindful communication with burnout, empathy, and attitudes among primary care physicians. JAMA 2009;302:1284-93. 